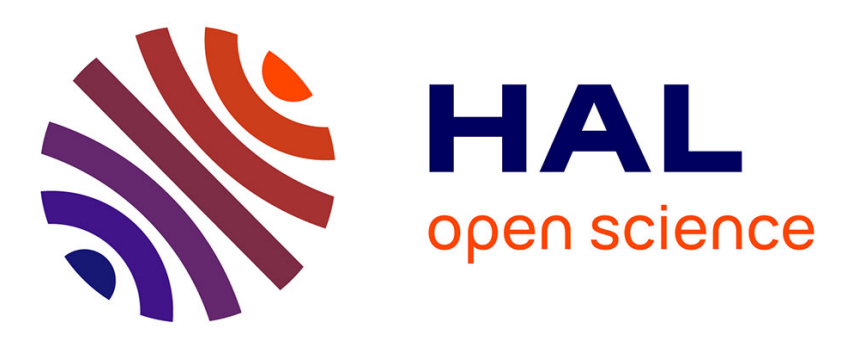

\title{
Oxidation of UC: An in situ high temperature environmental scanning electron microscopy study
}

Claudia Gasparrini, Renaud Podor, Denis Horlait, Michael J.D. Rushton, Olivier Fiquet, William Edward Lee

\section{- To cite this version:}

Claudia Gasparrini, Renaud Podor, Denis Horlait, Michael J.D. Rushton, Olivier Fiquet, et al.. Oxidation of UC: An in situ high temperature environmental scanning electron microscopy study. Journal of Nuclear Materials, 2017, 494, pp.127-137. 10.1016/j.jnucmat.2017.07.016 . hal-01996203

\section{HAL Id: hal-01996203 https://hal.science/hal-01996203}

Submitted on 25 Apr 2019

HAL is a multi-disciplinary open access archive for the deposit and dissemination of scientific research documents, whether they are published or not. The documents may come from teaching and research institutions in France or abroad, or from public or private research centers.
L'archive ouverte pluridisciplinaire HAL, est destinée au dépôt et à la diffusion de documents scientifiques de niveau recherche, publiés ou non, émanant des établissements d'enseignement et de recherche français ou étrangers, des laboratoires publics ou privés. 


\title{
Oxidation of UC: an in situ high temperature environmental scanning electron microscopy study
}

\author{
Claudia Gasparrini ${ }^{\mathrm{a}}$, Renaud Podor ${ }^{\mathrm{b}}$, Denis Horlait ${ }^{\mathrm{a}, \mathrm{c},}$ Michael J.D. Rushton ${ }^{\mathrm{a}}$, Olivier Fiquet $^{\mathrm{d}}$ \\ and William Edward Lee ${ }^{\mathrm{a}}$ \\ ${ }^{a}$ Centre for Nuclear Engineering $(C N E) \&$ Department of Materials, Imperial College London, South \\ Kensington Campus, London SW7 2AZ, U.K. \\ ${ }^{b}$ Institut de Chimie Séparative de Marcoule, UMR 5257 CEA/CNRS/UM/ENSCM, BP17171, 30207 Bagnols- \\ sur-Cèze, France \\ ${ }^{c}$ CNRS/IN2P3 and University of Bordeaux, Centre d'Etudes Nucléaires de Bordeaux-Gradignan, UMR 5797, \\ Chemin du Solarium, 33175 Gradignan, France \\ ${ }^{d}$ Commissariat à l'Energie Atomique, CEA, Cadarache, France \\ c.gasparrini14@imperial.ac.uk; renaud.podor@cea.fr; horlait@cenbg.in2p3.fr; m.rushton@imperial.ac.uk; \\ olivier.fiquet@cea.fr; w.e.lee@imperial.ac.uk
}

\begin{abstract}
In situ HT-ESEM oxidation of sintered UC fragments revealed the morphological changes occurring during the transformation between $\mathrm{UC}$ to $\mathrm{UO}_{2}$ and $\mathrm{UO}_{2}$ to $\mathrm{U}_{3} \mathrm{O}_{8}$ at 723 to $848 \mathrm{~K}$ and in an atmosphere of 10 to $100 \mathrm{~Pa} \mathrm{O}_{2}$. Two main oxidation pathways were revealed. Oxidation at $723 \mathrm{~K}$ in atmospheres $\leq 25 \mathrm{~Pa} \mathrm{O}_{2}$ showed the transformation from $\mathrm{UC}$ to $\mathrm{UO}_{2+\mathrm{x}}$, as confirmed by post mortem HRTEM analysis. This oxidation pathway was comprised of three steps: (i) an induction period, where only surface UC particles oxidised, (ii) a sample area expansion accompanied by crack formation and propagation, (iii) a stabilisation of the total crack length inferring that crack propagation had stopped. Samples oxidised under $50 \mathrm{~Pa}_{2}$ at $723 \mathrm{~K}$ and at 773 - $848 \mathrm{~K}$ for 10 to $100 \mathrm{~Pa} \mathrm{O}_{2}$ showed an "explosive" oxidation pathway: (i) sample area expansion occurred as soon as oxygen was inserted into the chamber and crack propagation and crack length followed an exponential law; (ii) cracks propagated as a network and the oxide layer fragmented, (iii) an "explosion" occurred causing a popcorn-like transformation, typical for oxidation from $\mathrm{UO}_{2}$ to $\mathrm{U}_{3} \mathrm{O}_{8}$. $\mathrm{HRTEM}$ characterisation revealed $\mathrm{U}_{3} \mathrm{O}_{8}$ preferentially grow in the [001] direction. The explosive growth, triggered by ignition of UC, proceeded as a self-propagating high-temperature synthesis reaction, with a propagation speed of $150-500 \pm 50 \mu \mathrm{m} / \mathrm{s}$.
\end{abstract}

Keywords: Uranium carbide - Uranium oxide - Oxidation - HT-ESEM -

\section{INTRODUCTION}

Uranium monocarbide (UC) has potential application as nuclear fuel for Generation IV reactors. The main advantages of this material compared to the current $\mathrm{UO}_{2}$ fuel are its higher fissile material density (1.34 times) and better thermal conductivity $\left(25.3 \mathrm{~W} /(\mathrm{m} \cdot \mathrm{K})\right.$ which is 2.6 times higher) ${ }^{1}$. While UC offers improved properties during use, at the end of the fuel cycle it cannot be safely stored or disposed of without undergoing preliminary conditioning to a suitable oxide form as it may be potentially pyrophoric and reactive with moisture and gases ${ }^{2,3}$. 
The mechanism of oxidation of uranium carbide was investigated in the 1960s and 1970s when interest in UC as a breeder reactor fuel was high ${ }^{4-9}$. It was found to be affected by several parameters such as temperature, oxygen partial pressure, morphology of the oxide layer formed, separation of the reaction products and stoichiometry of the initial material ${ }^{10}$. The oxidation mechanism of UC is complex as similar studies ${ }^{5,11}$ performed over the same temperature range and under the same oxygen atmosphere, suggest different oxidation mechanisms which are affected by the formation of a protective oxide layer or a low density non-protective pulverised oxide layer ${ }^{12,13}$. Indeed $\mathrm{U}_{3} \mathrm{O}_{8}$ appears to be a detachable powder whilst the thin layer adherent at the surface of uranium carbide is usually characterised as $\mathrm{UO}_{2}$ 14,15. Many aspects of the intermediate oxidation process that occur when $\mathrm{UO}_{2}$ is oxidised to $\mathrm{U}_{3} \mathrm{O}_{8}$ are not well understood. Oxidation of $\mathrm{UO}_{2}$ powders usually occurs in two stages represented by a pseudoparabolic weight gain curve followed by a sigmoidal curve ${ }^{16}$. The first part of the curve is characterised by a low oxidation rate, an induction period, that is associated with the diffusional oxidation of $\mathrm{UO}_{2}$ to $\mathrm{UO}_{2.34}$ with formation of $\mathrm{U}_{4} \mathrm{O}_{9}$ and $\mathrm{U}_{3} \mathrm{O}_{7}$ as intermediate products while the latter part of the curve assumes sigmoidal kinetics associated with the $\mathrm{U}_{3} \mathrm{O}_{8}$ nucleation and growth process ${ }^{16,17,18}$ that occurs when $\mathrm{U}_{3} \mathrm{O}_{8}$ is formed from $\mathrm{U}_{3} \mathrm{O}_{7}{ }^{16}$ or $\mathrm{UO}_{2}{ }^{18,19}$. The fcc cubic fluorite-type crystal structure of $\mathrm{UO}_{2}$ can accommodate extra oxygen atoms and therefore is able to form the polymorphs $\mathrm{U}_{4} \mathrm{O}_{9}$ and $\mathrm{U}_{3} \mathrm{O}_{7}$. These are described as $\mathrm{UO}_{2}$ matrices enriched with oxygen atoms ${ }^{20}$. Solubility of oxygen in $\mathrm{UO}_{2+\mathrm{x}}$ depends on temperature ${ }^{21}$ : above $773 \mathrm{~K}$ uranium oxides from $\mathrm{UO}_{2.26}-\mathrm{UO}_{2.33}$ can be converted to $\mathrm{U}_{3} \mathrm{O}_{8}{ }^{22}$.

UC oxidation occurs with the characteristic Maltese cross ${ }^{23}$ shape of the oxide, typical for carbides and borides of the group IV,V,VI of the transition metals ${ }^{24,25}$ when oxidised in $\mathrm{CO}_{2}$ atmosphere ${ }^{26}$ at 1073 $\mathrm{K}$ or in an atmosphere $\geq 13.3 \mathrm{kPa}$ in oxygen from $823-1073 \mathrm{~K}^{14,27}$.

Iyer et al. ${ }^{28}$ proposed a mechanism of oxidation for UC which involves: first the diffusion of oxygen into the uranium carbide matrix with the precipitation of carbon, reported to be highly reactive. The resulting oxycarbide is converted into uranium dioxide with subsequent precipitation of carbon as a second phase. This oxide acts as a diffusion barrier for oxygen transport through the carbide matrix ${ }^{28}$. It is unclear whether the oxide product readily spalls off or stays adherent to the carbide core, as contradictory results have been reported ${ }^{11,12,13}$. Mukerjee et al. ${ }^{11}$ proposed that at low oxygen partial pressures $(<5 \mathrm{kPa})$ the slow release of $\mathrm{CO}_{2}$ does not generate stresses in the oxide layer and therefore an intact oxide layer at the end of the reaction is formed.

The main reactions that can occur during the oxidation of UC are:

$$
\begin{aligned}
& \mathrm{UC}+\mathrm{O}_{2} \rightarrow \mathrm{UO}_{2}+\mathrm{C} \\
& \mathrm{C}+\mathrm{O}_{2} \rightarrow \mathrm{CO}_{2} \\
& 3 \mathrm{UO}_{2}+\mathrm{O}_{2} \rightarrow \mathrm{U}_{3} \mathrm{O}_{8}
\end{aligned}
$$

Reactions (1) and (2) occur at the same time, however reaction (3) is believed to occur when all the carbon is oxidised to $\mathrm{CO}_{2}{ }^{28}$. Slightly different reactions have been reported ${ }^{7}$ where the intermediate products of oxidation are $\mathrm{UC}_{2}, \mathrm{UO}_{2}, \mathrm{UC}_{1-x} \mathrm{O}_{x}, \mathrm{UO}_{3}$ or directly $\mathrm{U}_{3} \mathrm{O}_{8}$ and carbon could be oxidised either to $\mathrm{CO}$ or $\mathrm{CO}_{2}{ }^{14}$ depending on temperature and oxygen availability ${ }^{29}$. The presence of carbon increases the complexity of the oxidation mechanism of $\mathrm{UC}$ in comparison with oxidation of $\mathrm{UO}_{2}$ or metallic $\mathrm{U}$ as carbon can be found in the oxide as either free carbon, as carbide, as oxycarbide, as carbon monoxide or dioxide ${ }^{14}$. UC is well known to be pyrophoric ${ }^{3,28}$ and its ignition temperature is system dependant 
and is affected by several parameters such as heating rate, partial pressure of oxygen, and at least ten other factors including mass and specimen geometry ${ }^{2}$. The proposed UC ignition reaction ${ }^{28}$ is:

$\mathrm{UC}+\frac{7}{3} \mathrm{O}_{2} \rightarrow \frac{1}{3} \mathrm{U}_{3} \mathrm{O}_{8}+\mathrm{CO}_{2}$

It has been previously proposed that ignition in UC powder is triggered by the formation of a poorly crystallised and cracked layer of $\mathrm{UO}_{2}$ which does not offer protection to the $\mathrm{UC}$ core when being exposed to oxygen ${ }^{15}$. On the other hand, a stable and protective layer made of a solid solution $\mathrm{UCO} / \mathrm{UO}_{2-\mathrm{x}}$ would prevent ignition. The second path was found to be possible thanks to slow heating rates ${ }^{15}$.

The work presented in this paper is the first of its kind as it follows the in situ observation of morphological changes occurring during oxidation of sintered fragments of UC at low oxygen partial pressures $\left(\leq 100 \mathrm{~Pa} \mathrm{O}_{2}\right)$. This was made possible thanks to the use of state-of-the art techniques: hightemperature environmental scanning electron microscope (HT-ESEM) used for monitoring in situ oxidation of UC samples and post-mortem characterisation of the oxide products performed via high resolution transmission electron microscopy (HRTEM).

\section{EXPERIMENTAL}

High density disc shaped, ${ }^{235} \mathrm{U}$ depleted UC pellets ( $>91 \%$ of the theoretical density, TD, with U/C stoichiometry of $1.00 \pm 0.03$ ), were manufactured at CEA (Commissariat à l'Energie Atomique) Cadarache, France. They were crushed into fragments of various sizes and shapes with masses in the range 3.3-17.5 mg and stored in an inert glovebox. A value for the samples surface area before oxidation was evaluated by measuring the 3D sample dimensions from a SE image, approximating the third dimension as this was taken on a $2 \mathrm{D}$ image. The approximated samples height was considered to be even on all sides as this measurement could not be performed on each sample corner, the evaluated surface area was then divided by the sample mass and the values found were in the range of 1.6 - 9.7 $\mathrm{cm}^{2} / \mathrm{g}$. The insertion of the sample in the HT-ESEM was performed in air after removal of the UC fragment from the glovebox. The oxidation experiments were performed at the Institut de Chimie Séparative de Marcoule (ICSM) in Marcoule, France, in a HT-ESEM (FEI Quanta 200 FEG ESEM) equipped with a hot stage under an atmosphere of oxygen between 10 and $100 \mathrm{~Pa}$ oxygen. Samples were heated to the desired temperature, from 723 to $848 \mathrm{~K}$, under vacuum, and only after the required temperature was reached and stabilised, was the oxygen flux introduced into the chamber. A sample corner region, to study flat surfaces, edges and corners all at once, was continuously monitored for the entire length of the experiment and pictures were recorded every 3 or 5 seconds as soon as oxygen was inserted in the chamber and by default every 15 seconds after. All images were recorded with the same field of view, corresponding to an area of $908 \times 836 \mu \mathrm{m}^{2}$. The general procedure and details of the HTESEM platform may be found in refs ${ }^{30,31,32}$. Image analysis, using the Fiji ImageJ ${ }^{33}$ software, was used to monitor surface changes during isothermal heat treatments. Expansion of the sample surface and crack propagation due to the oxidation process was monitored by choosing specific features that identify a portion of the surface (the area highlighted in yellow in Figure 1a, b) and by manually tracking their change in position over time. The same area used to measure the dilatometric expansion of the sample was used to analyse crack coverage (Figure 1b). Cracks were highlighted in the figure, by choosing a 
threshold level in the image values contrast (in this case threshold $=10$ out of 255 where 0 is black and 255 is white) allowing the dark regions lying below the threshold, to be identified as cracks. The result of the analysis is a two-dimensional value of the area covered by the cracks on the selected region. Data were then normalised to the value measured at time $\mathrm{t}=0$ which represents the moment when oxygen was inserted in the chamber, so that values are expressed in \%. The initial value was subtracted from the following measurements so that the increment of sample expansion and crack propagation is tracked from an initial zero value and therefore comparison between different experiments is possible. A process called skeletonization was applied in order to evaluate the crack network. This involve a binary thinning process which is used to find the centrelines, or skeletons, of objects ${ }^{34}$. By using the plugins Skeletonize (2D/3D) and Analyse Skeleton (2D/3D) ${ }^{35}$ available in ImageJ it is possible to quantify crack length and crack network by counting crack junctions (Figure 1c). Cracks branching were evaluated with the number of junctions provided through the Analyse Skeleton technique. Sample overall expansion was evaluated with Fiji ImageJ by tracking sample borders and measuring this area before and after oxidation (Figures $2 \mathrm{a}$ and $\mathrm{b}$ ).

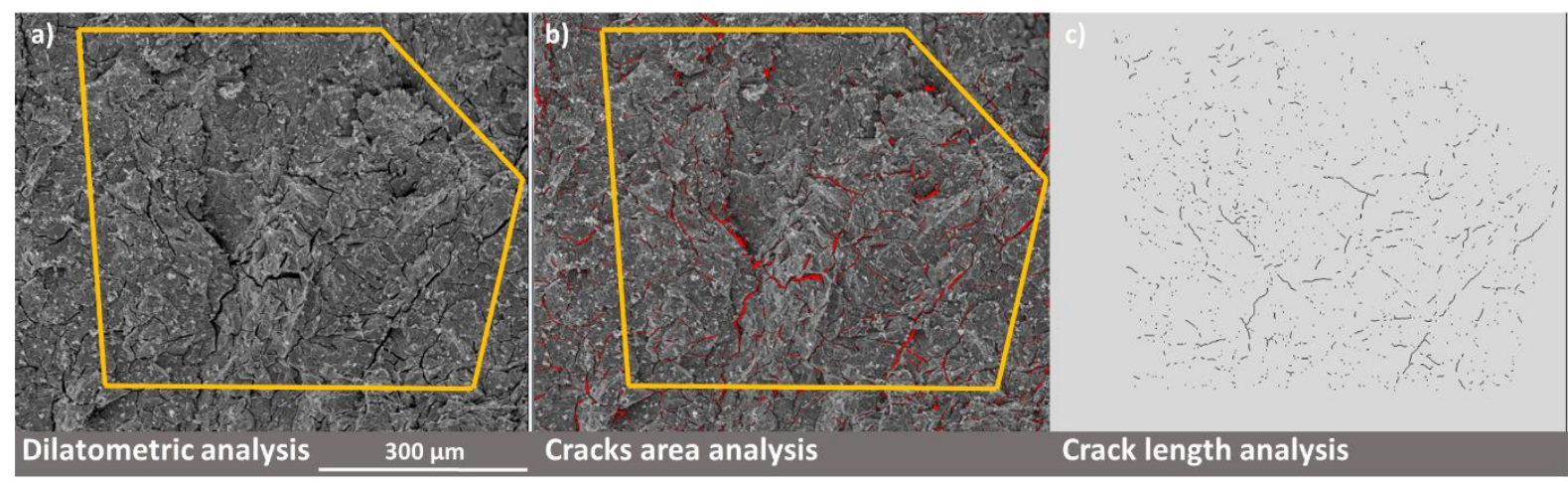

Figure 1 Image analysis on SE images of UC fragment oxidised at $723 \mathrm{~K}$ in a $10 \mathrm{~Pa} \mathrm{O}_{2}$ atmosphere: the tracked area chosen for the dilatometric analysis and crack propagation is highlighted in yellow in a) and b). Crack length is evaluated by skeletonization of the cracks area (Figure c)

Secondary Electron Image (SEI) characterisation on the oxide powder after oxidation was performed with the HT-ESEM used in SEM mode. Nanoscale characterisation of the oxide product was performed at Imperial College with a high resolution transmission electron microscope (HRTEM) (JEOL 2100Plus, Tokyo, Japan) in bright field (BF) imaging mode. Selected area diffraction (SAD) patterns were indexed by matching the $\mathrm{d}_{\mathrm{hkl}}$ values with reference patterns obtained from the powder diffraction file in the ICDD (International Centre for Diffraction Data) database. Samples for TEM analysis were prepared by crushing the oxide product diluted in pure ethanol with an agate pestle. $10 \mu \mathrm{l}$ of ethanol solution with the ground oxide powders was then deposited on a carbon-coated TEM copper grid.

\section{RESULTS \& DISCUSSIONS}

Two oxidation pathways were found which are characterised by a non explosive or an explosive nature. The results section is therefore divided into two parts labelled as pathway 1 for the former and pathway 2 for the latter. The word explosive here has been used with the meaning of "a sudden and dramatic increase of the sample expansion which lead to a shattered and pulverised oxide". In comparison with 
what was suggested by Mukerjee et al. work ${ }^{11}$, this study shows that partial pressures as low as $2 \mathrm{~Pa}$ $\mathrm{O}_{2}$ lead to a cracked oxide layer.

\section{- Pathway 1: Non explosive (exponential then logarithmic increase of sample expansion)}

Figure $2 \mathrm{a}$ and $\mathrm{b}$ show SE images of a UC sample oxidised in $10 \mathrm{~Pa}$ oxygen atmosphere at $723 \mathrm{~K}$ in the HT-ESEM before and after the experiment. The sample outline at the end of the experiment was 2.5 times larger (Figure 2b) and the apparent volume gain is 5 times. SEM analysis of the powder after oxidation showed that the oxide layer presented macrocracks and microcracks on the surface (Figure 2c) but still displays a compact structure. The surface morphological changes occurring during oxidation are shown in Figures 2 d, e and f. After an initial induction period (approximately 1 hour) where the sample surface appeared to remain compact and where only small crystals (approximately 3 $\mu \mathrm{m}$ wide) deposited on the surface oxidised, macro cracks started to appear over the entire surface. Cracks were evenly distributed at corners and on the sample's surface and their propagation was accompanied by a considerable sample volume expansion as the sample corner left the field of view (Figure 2f). The sample surface seen after $14 \mathrm{~h}$ of exposure in $723 \mathrm{~K}, 10 \mathrm{~Pa}$ oxygen atmosphere (Figure 2f) remained still as cracks were no longer propagating, the experiment was stopped at this stage by decreasing the furnace temperature to room temperature.

Post mortem HRTEM analysis on oxide powders revealed that oxide particles are about $5 \mathrm{~nm}$ in size (Figures $2 \mathrm{~g}$ and $\mathrm{h}$ ). Bright-field TEM imaging (Figure $2 \mathrm{~h}$ ) determined that the oxide shown in Figure $2 \mathrm{c}$ is mostly comprised of randomly oriented nanocrystals. A SAD pattern obtained from this region (Figure 2i) showed that this oxide is polycrystalline $\mathrm{UO}_{2}$ (matched with PDF 00-041-1422 $\mathrm{UO}_{2}$, cubic Fm-3m). Diffraction patterns for uranium oxide compounds however can be very similar, for example tetragonal $\mathrm{U}_{3} \mathrm{O}_{7}$, cubic $\mathrm{U}_{4} \mathrm{O}_{9}$ and $\mathrm{UO}_{2}$ (see $\mathrm{PDF} 00$ - 015 - 0004, $01-075$ - 0944 and $00-041-1422$, respectively) show very close patterns, therefore the presence of $\mathrm{U}_{4} \mathrm{O}_{9}$ or $\mathrm{U}_{3} \mathrm{O}_{7}$ cannot be ruled out. 

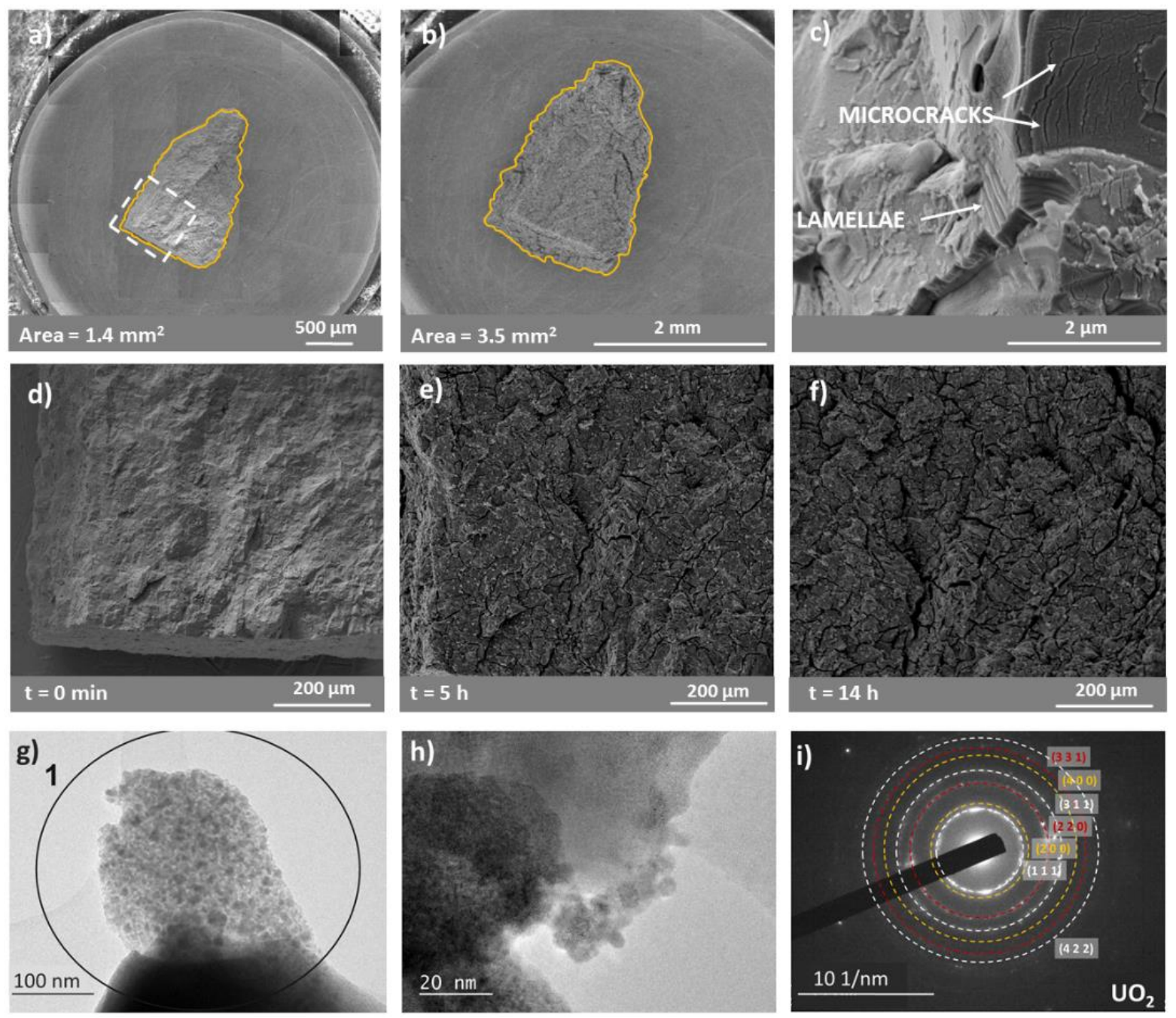

Figure 2 UC fragment oxidised at $723 \mathrm{~K}$ in a $10 \mathrm{~Pa} \mathrm{O}_{2}$ atmosphere: SE images a) before and b) after oxidation; yellow line highlights the outline of the sample, the dashed white square highlights the corner chosen to monitor the surface during the experiment (Figures d, e and f); post mortem high magnification SEI of oxide powder c) details of microcracks on the top surface and oxide layers organised in form of lamellae adherent to the oxide; sequence of SEI showing in situ oxidation d) before oxidation, e) $5 \mathrm{~h}$ after oxygen insertion and f) 14 hours after oxygen insertion; BF TEM image of the oxide powder shown in Figure 2c) g) details of the aperture, labelled 1, used to obtain SAD pattern, h) high magnification BFTEM image of the uranium oxide nanocrystals; i) SAD pattern obtained from region 1 in Figure $2 \mathrm{~g}$ showing rings matching cubic $\mathrm{UO}_{2}$

Figures 3a shows plots of sample dilatometric expansion of the surface during oxidation. The same trend can be seen for crack propagation (Figure 3c) which cannot be described by a simple kinetic law, as it resembles sigmoidal behaviour. Plotting values for the area expansion in $\%$ on a logarithmic scale versus time (Figure $3 \mathrm{~b}$ ) revealed that the last part of the curve can be described by a linear fit, indicating that oxidation proceeded with a logarithmic law, typical of low temperature oxidation in metals ${ }^{36}$. UC oxidation developed rapidly at the beginning when the first cracks were formed. After a given time, approximately 6 hours after oxygen insertion, the rate of cracks propagation decreased. As can be seen in Figure 3c, at the end of the experiment the area of cracks still increased but the overall crack length (calculated from the skeletonised data) stabilised inferring that no new cracks were formed. This indicates that cracks entered a regime in which the existing cracks opened and potentially increased in 
depth. The reported values of cracks area and crack length are here used for qualitative considerations and comparison.

a)

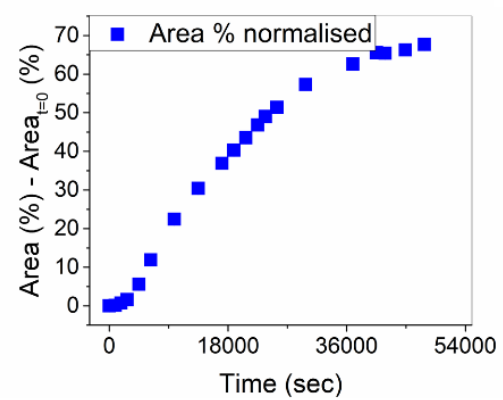

b)

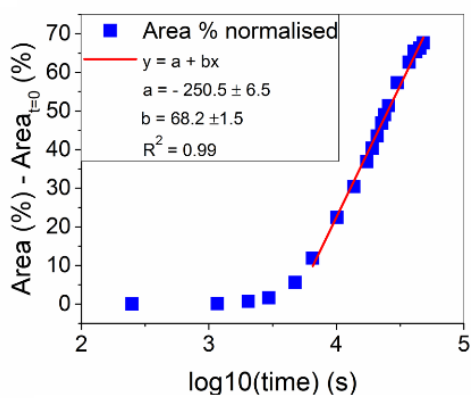

c)

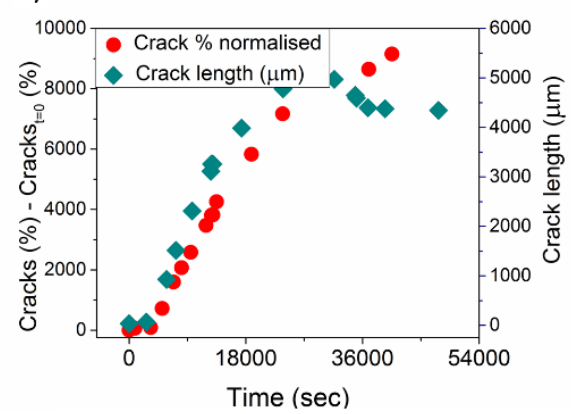

Figure 3a) Plot of the dilatometric area analysis in $\%$ vs. time and b) plots of area analysis in $\%$ vs. $\log _{10}$ time and c) cracks in $\%$ over the entire surface vs. time, and crack length $(\mu \mathrm{m})$ sample oxidised at $723 \mathrm{~K}$ in $10 \mathrm{~Pa} \mathrm{O}_{2}$

\section{Pathway 2: Explosive growth (sudden and dramatic sample expansion)}

The same heating procedure was applied to another UC sample oxidised also at $723 \mathrm{~K}$, but at a higher partial pressure of oxygen, $50 \mathrm{~Pa}$. SEI obtained during in situ oxidation (Figure 4) revealed that the sample after oxidation showed a completely different shape (Figure 4b) and it was not possible to identify the original outline of the sample. The overall lateral sample expansion is measured as almost 10 times in size (Figures $4 \mathrm{a}, \mathrm{b}$ ) and the overall apparent volume expansion is estimated to be $\sim 26$ times. Figure $4 \mathrm{c}$ shows a high magnification image of the oxide after oxidation. The oxide conformation seen at the end of the experiment resembles the characteristic cauliflower morphology, or also known as popcorn-like transformation ${ }^{17}$, named after the change from $\mathrm{UO}_{2}$ to $\mathrm{U}_{3} \mathrm{O}_{8}$. In this study, the popcornlike expansion was monitored for the first time in situ during UC oxidation. This transformation was observed after the sample had increased in volume and an explosive expansion occurred (Figures 4d, e, f). Figure $4 \mathrm{~d}$ is a SEI of the sample surface at the beginning of the oxidation, $4 \mathrm{e}$ is a SEI of the sample after 17 minutes of oxygen exposure where the sample has expanded and cracks are visible (top of the image), while the sample explosion initiation is seen on the bottom of this picture. This transformation happened in the frame time of this SE image scanning (a few seconds). The next image, Figure 4f, captured 15 seconds later demonstrates the quasi-instantaneous change in sample morphology. Figure $4 \mathrm{c}$ shows the oxide morphology after the explosive event which has a structure that is opened in comparison to the oxide shown in Figure $2 \mathrm{c}$ and shows the characteristic popcorn-like morphology of $\mathrm{U}_{3} \mathrm{O}_{8}$ formed by $\mathrm{UO}_{2}$ oxidation ${ }^{17,37}$.

The formation of $\mathrm{U}_{3} \mathrm{O}_{8}$ (and $\mathrm{U}_{3} \mathrm{O}_{7}$ ) at the end of the $50 \mathrm{~Pa} \mathrm{O}_{2}$ experiment was confirmed by TEM characterisation. Figure $4 \mathrm{~g}$ shows a BF TEM image of the oxide powder formed at the end of the in situ oxidation while Figure $4 \mathrm{~h}$ shows the SAD pattern obtained from the area labelled as 1 . The SAD ring pattern matches with a polycrystalline biphasic sample made of orthorhombic $\mathrm{U}_{3} \mathrm{O}_{8}$ and tetragonal $\mathrm{U}_{3} \mathrm{O}_{7}$ (PDF $00-031-1424$ and $00-015-0004$, respectively). Confirmation of the presence of a mixture of $\mathrm{U}_{3} \mathrm{O}_{7} / \mathrm{U}_{3} \mathrm{O}_{8}$ in the $\mathrm{SAD}$ analysis obtained for the sample oxidised at $723 \mathrm{~K}$ can also be deduced from the phase diagram reported by Higgs et al. ${ }^{38}$ : for high oxygen/uranium ratio $\mathrm{U}_{3} \mathrm{O}_{8}$ is reported to be present in a mixture with $\mathrm{U}_{3} \mathrm{O}_{7}$ for temperatures below $780 \mathrm{~K}$. On the other hand, above $780 \mathrm{~K}$ instead, $\mathrm{U}_{3} \mathrm{O}_{8}$ is expected to be present in a mixture with $\mathrm{U}_{4} \mathrm{O}_{9}{ }^{38,39}$. 

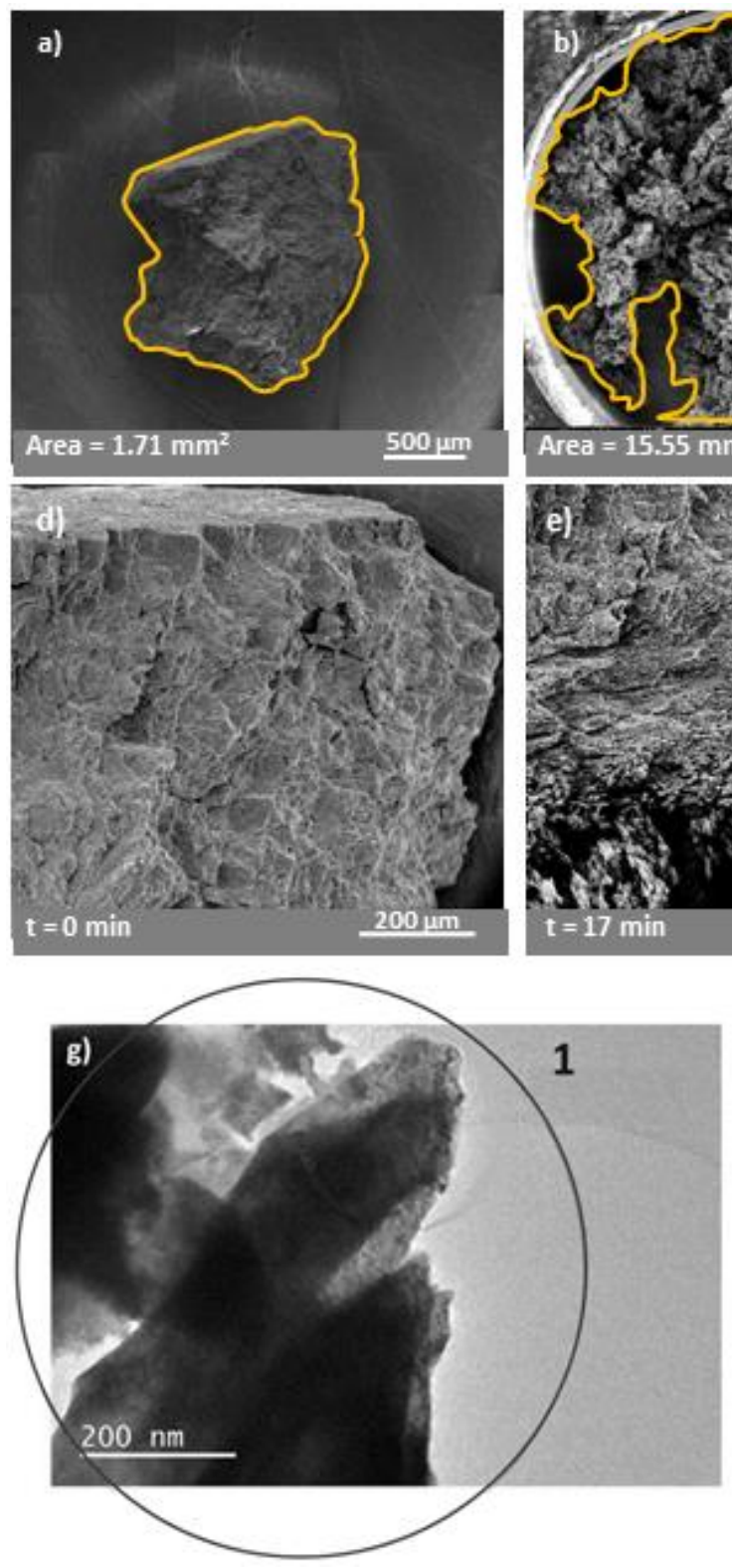
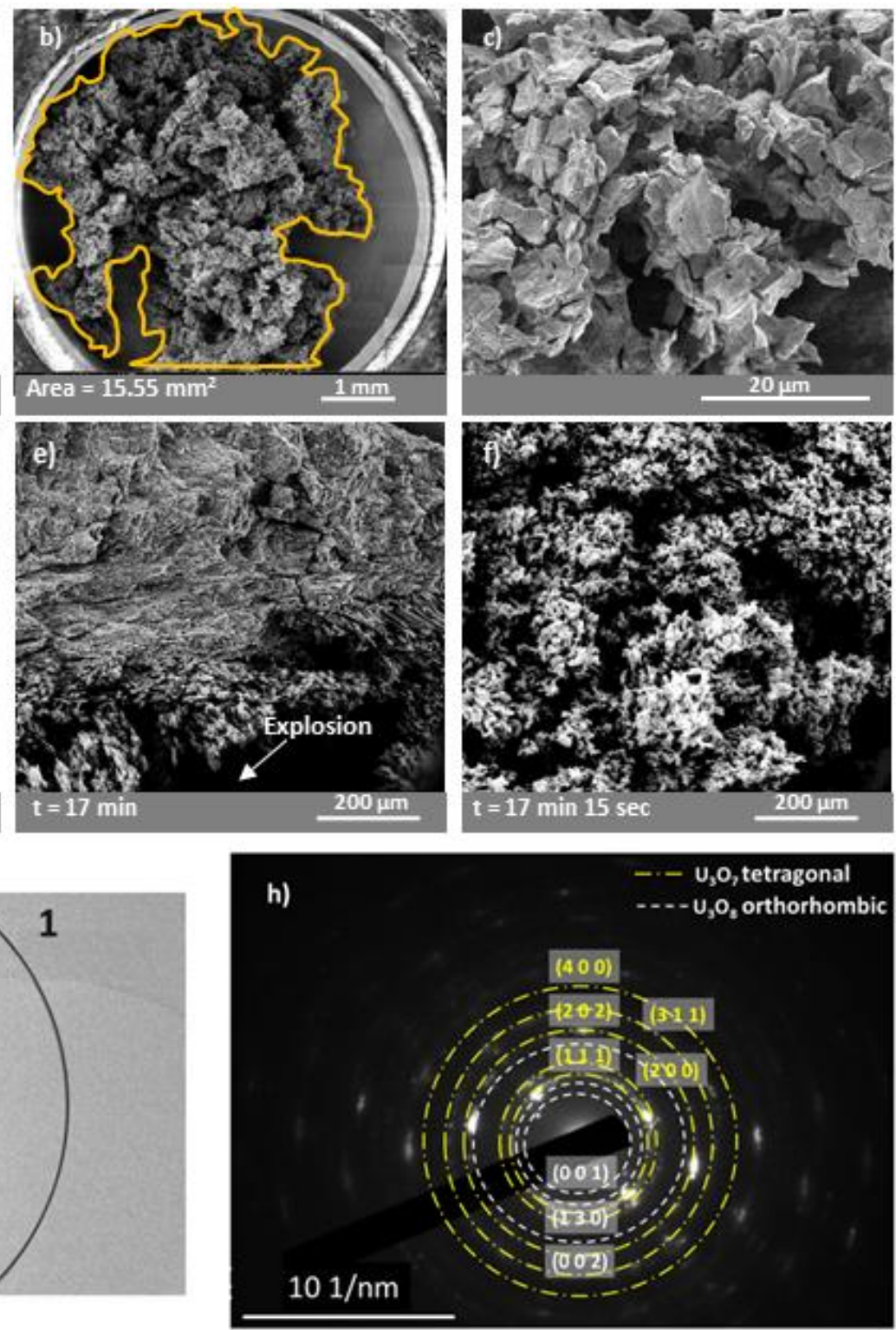

Figure $4 \mathrm{UC}$ fragment oxidised at $723 \mathrm{~K}$ in a $50 \mathrm{~Pa} \mathrm{O}_{2}$ atmosphere: $\mathrm{SE}$ images a) before oxidation b) after oxidation; c) high magnification SEI of the oxide; sequence of SEI showing in situ oxidation d) just after oxygen insertion, e) 17 minutes after oxygen insertion showing sample explosive expansion occurring during the image scan time frame, f) 15 seconds after SEI e) showing the sample surface after explosion, g) BF TEM image of the oxide powder, h) SAD pattern of region labelled as $\mathbf{1}$ showing rings that match orthorhombic $\mathrm{U}_{3} \mathrm{O}_{8}$ and tetragonal $\mathrm{U}_{3} \mathrm{O}_{7}$.

Results obtained from image processing of the images of the sample surface are reported in Figure 5. The last data point in Figures 5 belongs to the sample just before explosion (no data can obviously be recorded after). The curves showing the variation of the normalised area expansion $\%$ and area of cracks $\%$ for the sample oxidised at $723 \mathrm{~K}$ in $50 \mathrm{~Pa}$ in $\mathrm{O}_{2}$ (see Figure 5 a and b) follow the same trend. This time they fit with an exponential growth curve of type:

$y=A e^{\left(x / t_{1}\right)}$ 
where $\mathrm{A}$ is a positive growth factor and $\mathrm{t}_{1}$ is a time constant which represents the time required for the function $\mathrm{y}$, which is either the area $\%$ or cracks $\%$, to increase by one factor equal to $e$. The sample exposed to $50 \mathrm{~Pa} \mathrm{O}_{2}$ oxidised at a much higher rate compared to the sample exposed to $10 \mathrm{~Pa}_{2}$, the experiment was completed within 18 minutes at $50 \mathrm{~Pa}$ compared to the 14 hours exposure at $10 \mathrm{~Pa}_{2}$. No induction time was observed for the sample at $50 \mathrm{~Pa} \mathrm{O}_{2}$. Instead crack propagation and sample expansion directly grew exponentially when oxygen was let into the chamber.

a)

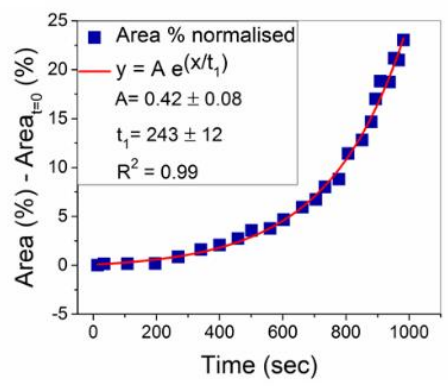

b)

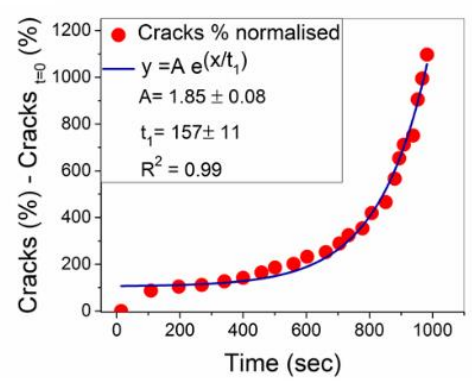

c)

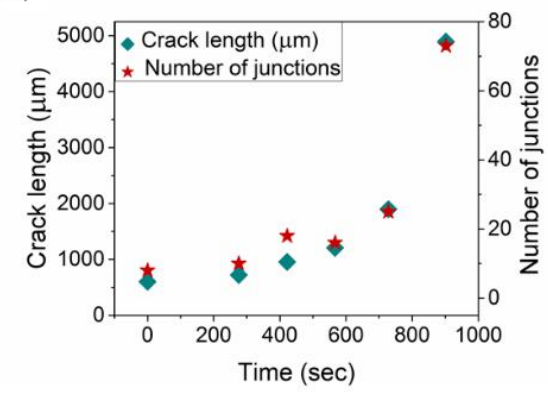

Figure 5 a) Plot of the dilatometric area analysis in $\% v s$. time and b) crack area analysis in $\%$ vs. time. Fittings performed with exponential laws. c) crack length $v s$. number of junctions analysis comparison, sample oxidised at $723 \mathrm{~K}$ in $50 \mathrm{~Pa} \mathrm{O}_{2}$

The popcorn-like explosion observed in Figure $4 \mathrm{e}$ also occurred for all the samples oxidised in the range of 773-848 $\mathrm{K}$ in a $10-100 \mathrm{~Pa} \mathrm{O}_{2}$ atmosphere. Cracks formation was monitored thoroughly in the sample oxidised at $848 \mathrm{~K}$ in $10 \mathrm{~Pa} \mathrm{O}_{2}$. Figure 6 shows the stages occurring just before and during the explosive growth by oxidation of a UC sample. Fragmentation of the sample surface occurred in the area where the disruption of the sample initiated (Figure 6d). The slow motion explosion visible in Figure 6 consists of images recorded every second instead of the usual 15 seconds. The progress of this explosion (Figures 6d-h) is similar to a runaway reaction such as a self-propagating high-temperature synthesis, or SHS, initiated with the ignition of UC. The propagation front from the initiation point seen in Figure 6d travelled with a speed between $150-500 \pm 50 \mu \mathrm{m} / \mathrm{s}$ across the sample. This was evaluated by measuring the distance between the explosion front with the bottom left sample corner seen in Figure $6 \mathrm{~h}$.
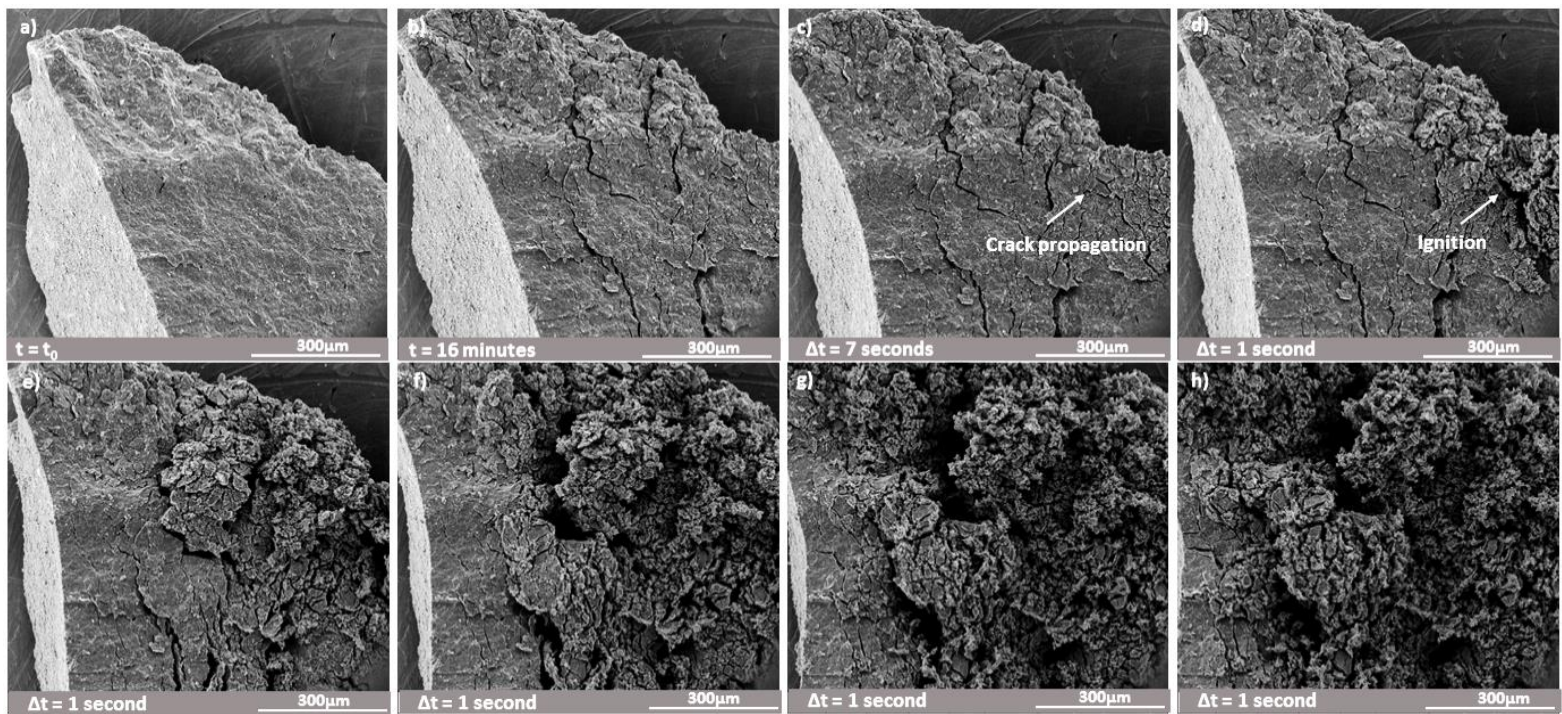
Figure 6 Sequence of SE images of UC fragment oxidised at $848 \mathrm{~K}$ in $10 \mathrm{~Pa} \mathrm{O}_{2}$ a) just after insertion of oxygen b) after 16 minutes from oxygen insertion c) after 16 minutes and 7 seconds: crack propagation is evident on the top right corner, d) to $\mathrm{h}$ ) sequence of SE images taken 1 second apart showing the progress of the sample ignition.

Self-sustaining reactions can occur either between solids but also between gases and solids ${ }^{40}$. In order to have a SHS, the reaction considered must be highly exothermic ${ }^{40}$, like in this system, as can be seen in Table 1.

The standard enthalpy and entropy of reaction $\Delta_{\mathrm{r}} \mathrm{H}^{0}$ and $\Delta_{\mathrm{r}} \mathrm{S}^{0}$ along with the standard Gibbs enthalpy of the reaction $\Delta_{\mathrm{r}} \mathrm{G}^{0}$ have been evaluated with equations 6 and 7 and these are shown in Table 1:

$\Delta_{r} X=\sum_{i} r_{i} \Delta_{f} X_{i}^{0}$

$\Delta_{r} G^{0}=\Delta_{r} H^{0}-T \Delta_{r} S^{0}$

where $\mathrm{X}$ is either the enthalpy $\mathrm{H}$ or entropy $\mathrm{S}, \mathrm{r}>0$ for products and $\mathrm{r}<0$ for reactants. The UC ignition reaction shown in Equation 4 has the highest standard enthalpy of reaction, $\Delta_{\mathrm{r}} \mathrm{H}^{0}$, measured as -1487 $\mathrm{kJ} / \mathrm{mol}$. This means that UC ignition releases the highest amount of energy in comparison with all the possible reactions that can occur within this system and this may explain the triggering of the SHS. Also UC ignition has the highest standard Gibbs enthalpy of the reaction which shows that it is the most spontaneous reaction in this system.

Table 1. Enthalpies of formation $\left(\Delta_{\mathrm{f}} \mathrm{H}^{0}\right)$ for the species in this system, standard enthalpy and entropy of reaction $\left(\Delta_{\mathrm{r}} \mathrm{H}^{0}, \Delta_{\mathrm{r}} \mathrm{S}^{0}\right)$ and standard Gibbs enthalpy of the reaction $\left(\Delta_{\mathrm{r}} \mathrm{G}^{0}\right)$

\begin{tabular}{|c|c|c|c|c|c|c|c|}
\hline Species & $\begin{array}{c}\Delta_{\mathrm{f}} \mathrm{H}^{0} \\
(298.15 \mathrm{~K}) \\
\left(\mathrm{kJmol}^{-1}\right)\end{array}$ & $\begin{array}{c}\mathrm{S}^{0} \\
(298.15 \mathrm{~K}) \\
\left(\mathrm{JK}^{-1} \mathrm{~mol}^{-1}\right)\end{array}$ & $\begin{array}{c}\text { Reaction } \\
\text { (equation } \\
\left.\mathbf{n}^{\circ}\right)\end{array}$ & $\begin{array}{c}\Delta_{\mathrm{r}} \mathrm{H}^{0} \\
(298.15 \mathrm{~K}) \\
\left(\mathrm{kJ} / \mathrm{mol}^{-1}\right)\end{array}$ & $\begin{array}{c}\Delta_{\mathrm{r}} \mathrm{S}^{\mathbf{0}} \\
(298.15 \mathrm{~K}) \\
\left(\mathrm{J} / \mathrm{K}^{-1} \mathbf{m o l}^{-1}\right)\end{array}$ & $\begin{array}{c}\Delta_{\mathrm{r}} \mathrm{G}^{0} \\
(298.15 \mathrm{~K}) \\
\left(\mathrm{kJ} / \mathrm{mol}^{-1}\right)\end{array}$ & $\begin{array}{c}\text { Referen } \\
\text { ce }\end{array}$ \\
\hline UC & $-97.9 \pm 4.0$ & 59.3 & & & & & 14 \\
\hline $\mathrm{CO}_{2}$ & -394.4 & 213.6 & & -393.5 & & & \\
\hline $\mathrm{C}(\mathrm{s})$ & & 5.7 & & & & & \\
\hline $\mathrm{O}_{2}$ & & 205 & & & & & \\
\hline $\mathbf{U O}_{2}$ & $-1085.0 \pm 1.0$ & 77.03 & (1) & -987.1 & -181.6 & -932.9 & 41 \\
\hline \multirow[t]{2}{*}{$\mathrm{U}_{3} \mathrm{O}_{8}$} & $-3574.8 \pm 2.5$ & 282.54 & $\begin{array}{l}(3) \\
(4)\end{array}$ & -319.8 & -153.6 & -274.1 & 41 \\
\hline & & & & -1487.21 & -229.9 & -1419.6 & 2 \\
\hline
\end{tabular}

Crack area analysis and crack length analysis on the sample performed just before the explosion is shown in Figure 7a. A drastic increase in crack length and number of junctions occurred before the sample was disrupted, these were measured on pictures taken before Figure $6 \mathrm{c}$. The drastic increase of these two parameters shows that cracks propagated forming a network before the sample explosion occurred. The time to reach this last oxidation step, characteristic for UC oxidation, is here called "ignition time". The dependence of the ignition time with temperature and oxygen partial pressure from 
773 to $848 \mathrm{~K}$, in an oxygen atmosphere from 10 to $100 \mathrm{~Pa} \mathrm{O}_{2}$ is shown in Figures $7 \mathrm{~b}$ and c. A similar trend is shown: by increasing the temperature or oxygen partial pressure the ignition time is reduced. The same transformation seen in the sample oxidised at $723 \mathrm{~K}$ in $50 \mathrm{~Pa} \mathrm{O}_{2}$ occurred for all samples tested in this range of oxygen pressure and temperature. UC oxidised as soon as oxygen was added to the chamber, no induction period was observed and sample area expansion and crack propagation grew exponentially until reaching the point of no-return where explosion occurred.

a)

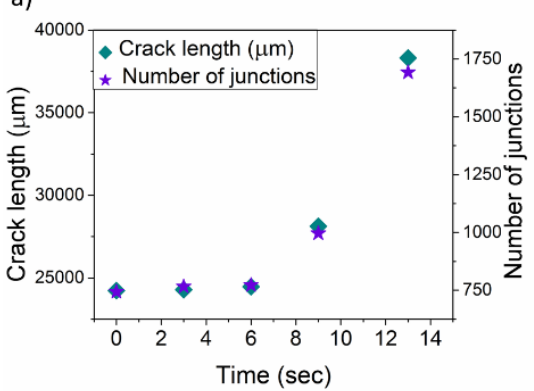

b)

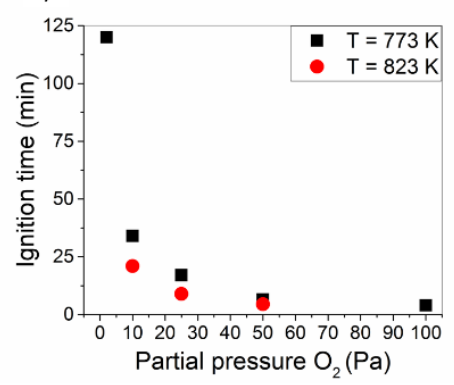

c)

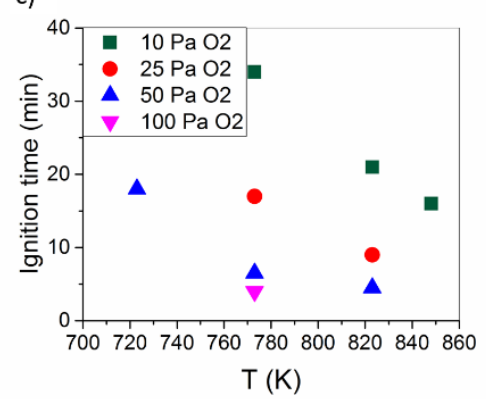

Figure 7 a) Plot of the crack length and number of junctions $v s$. time just before ignition of sample oxidised at $848 \mathrm{~K}$ in $10 \mathrm{~Pa} \mathrm{O}_{2}$; Correlation of the ignition time with oxygen partial pressure b) and with temperature c) for UC samples oxidised from $723 \mathrm{~K}$ to $848 \mathrm{~K}$ in an oxygen atmosphere between $10-100 \mathrm{~Pa}$.

The characteristic popcorn-like morphology of $\mathrm{U}_{3} \mathrm{O}_{8}$ previously reported in the literature ${ }^{17,37}$ for the conversion from $\mathrm{UO}_{2}$ to $\mathrm{U}_{3} \mathrm{O}_{8}$ was monitored during in situ oxidation of $\mathrm{UC}$ in the range of temperature from 723 to $848 \mathrm{~K}$. The influence of surface morphological changes such as crack propagation was here used to describe the mechanism of oxidation and ignition of UC. The characterisation of oxidation mechanisms via crack analysis is an unusual method in comparison with the widely used method of weight gain curves. However, Lefort et al. ${ }^{42}$ previously characterised the sigmoidal weight gain curves typical for oxidation of cubic niobium nitride thanks to the development of a fragmentation model.

UC oxidation was observed to follow two types of process: (1) an oxidation where sample area and crack propagation are characterised by an induction time followed by a drastic increase which then slowed to low rates forming $\mathrm{UO}_{2}$ or (2) a drastic oxidation where sample expansion and crack propagation are observed to start as soon as oxygen is inserted in the chamber followed by an exponential growth until an explosion (i.e. an instantaneous and dramatic increase of growth rate) occurred. At this stage sample morphology is changed into a popcorn-like shape were a mixture of $\mathrm{U}_{3} \mathrm{O}_{8} / \mathrm{U}_{3} \mathrm{O}_{7}$ is formed. The reason for occurrence of either one of the two types of oxidation was found to be strictly related to both partial pressure of oxygen and temperature. Furthermore, the time needed for the ignition to occur, here called ignition time, (see Figures $7 b$ and c) is influenced by both parameters. This is in agreement with Matzke, who reported that both the reaction of carbon with oxygen and the dissolution of oxygen in the carbide during oxidation of uranium carbide are strictly linked with both partial pressure of oxygen and temperature ${ }^{14}$.

By examining the first stages of reactions occurring at $723 \mathrm{~K}$, it is possible to see that samples oxidised at 10 and $25 \mathrm{~Pa} \mathrm{O}_{2}$ followed pathway 1, while the sample oxidised at $50 \mathrm{~Pa} \mathrm{O}_{2}$ followed pathway 2 (Figure 8a). Samples exposed to $10 \mathrm{~Pa}$ showed an induction time of approximately 1 hour while the sample exposed to $25 \mathrm{~Pa} \mathrm{O}_{2}$ presented a 15 minutes induction time. The induction time is 4 times shorter when the atmosphere is changed from 10 to $25 \mathrm{~Pa}$ of oxygen. It is therefore plausible to assume that for 
the curve at $50 \mathrm{~Pa}$ the induction time is either too short to be experimentally observed or that pathway 2 is characterised by the absence of an incubation time.

At higher temperatures, such as $773 \mathrm{~K}$, samples followed pathway 2 for all pressures tested, from 10$100 \mathrm{~Pa} \mathrm{O}_{2}$ (see Figure 8c). The plots of normalised area\% vs. time were fitted with the exponential law shown in Equation 5.

a)

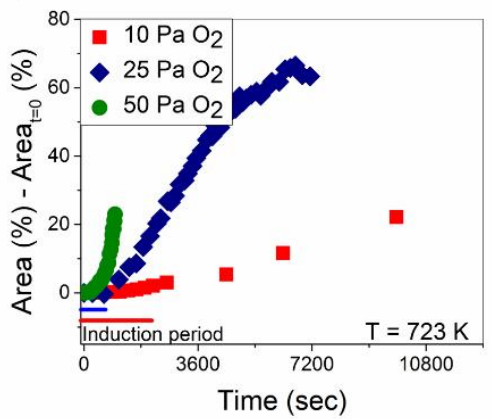

b)

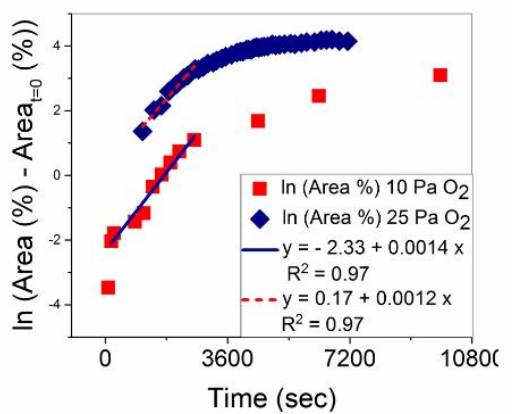

c)

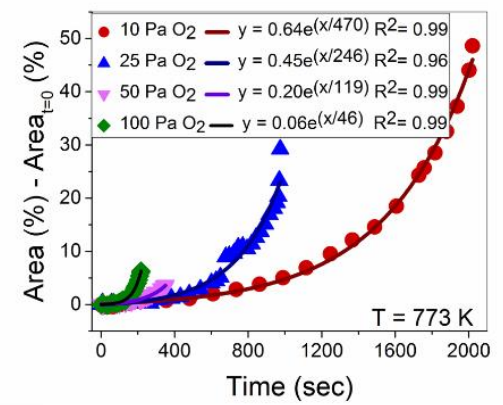

Figure 8 Plot of the normalised area in \% vs. time for a) UC samples oxidised at T=723 K in an atmosphere of $10 \mathrm{~Pa} \mathrm{O}_{2}(\bullet), 25 \mathrm{~Pa} \mathrm{O}_{2}(\bullet)$ and $50 \mathrm{~Pa}_{2}(\bullet)$; b) logarithmic fit for the normalised area for samples that follow pathway 1: $10(\boldsymbol{\bullet})$ and $25 \mathrm{~Pa} \mathrm{O}_{2}(\bullet)$ at $723 \mathrm{~K} \mathrm{c}$ ) normalised area in \% vs. time for UC samples oxidised at $\mathrm{T}=773$ $\mathrm{K}$ in an atmosphere of $10 \mathrm{PaO}_{2}(\bullet), 25 \mathrm{~Pa} \mathrm{O}_{2}(\boldsymbol{\Delta}), 50 \mathrm{PaO}_{2}(\boldsymbol{\nabla})$ and $100 \mathrm{~Pa}_{2}(\bullet)$

The time constant $\mathrm{t}_{1}$, was directly evaluated for all curves that fit Equation 5 as shown in Figure 8c. Time constants $t_{1}$ for samples that followed mechanism 1 were found by plotting the natural logarithm of the normalised area $\% v s$. time and by linearly fitting the initial part of the curve, after the induction time. In this case the time constant $t_{1}$ is the inverse of the slope of the straight line fitted in Figure $8 b$ (see Equation 8).

$\ln (y)=\ln (A)+\frac{1}{t_{1}} x$

Table 2 summarises the time constants for the samples oxidised at $723 \mathrm{~K}$ from $10-50 \mathrm{~Pa} \mathrm{O}_{2}$ and at 773 $\mathrm{K}$ from $10-100 \mathrm{~Pa} \mathrm{O}_{2}$.

Table 2. Time constants $\mathrm{t}_{1}$ (seconds) evaluated for samples oxidised at $723 \mathrm{~K}$ and $773 \mathrm{~K}$ in an atmosphere from 10-100 $\mathrm{Pa} \mathrm{O}_{2}$

Partial Pressure $\mathrm{O}_{2}$

10

25

50

100

(Pa)

\section{Temperature $(\mathbf{K})$}

\begin{tabular}{ccccc}
\hline $723 \mathbf{K}$ & $740 \pm 49$ & $820 \pm 53$ & $243 \pm 12$ & \\
\hline $\mathbf{7 7 3} \mathbf{K}$ & $470 \pm 14$ & $246 \pm 25$ & $119 \pm 9$ & $46 \pm 2$ \\
\hline
\end{tabular}

The time constant error for samples oxidised at $723 \mathrm{~K}$ at 10 and $25 \mathrm{~Pa}$ was found by using Equation 9:

$\delta t_{1}=\frac{\delta \frac{1}{t_{1}}}{\frac{1}{t_{1}}} \cdot t_{1}$

where the error $\delta \frac{1}{t_{1}}$ is given by the fitting of the plot in Figure $8 \mathrm{~b}$. 
The change in oxidation pathway from 1 to 2 is characterised by a different value of $t_{1}$. Values of $t_{1}$ higher or equal to $740 \pm 49$ seconds characterise pathway 1 which represent the non-explosive oxidation. Conversely, values of $t_{1}$ smaller or equal to $470 \pm 14$ seconds characterise the explosive pathway. In this case the area increase and cracks propagation occur rapidly. Sample fragmentation leads to UC ignition which in turn triggers the explosion of the entire sample. Figure 9 is a schematic of the two oxidation processes.
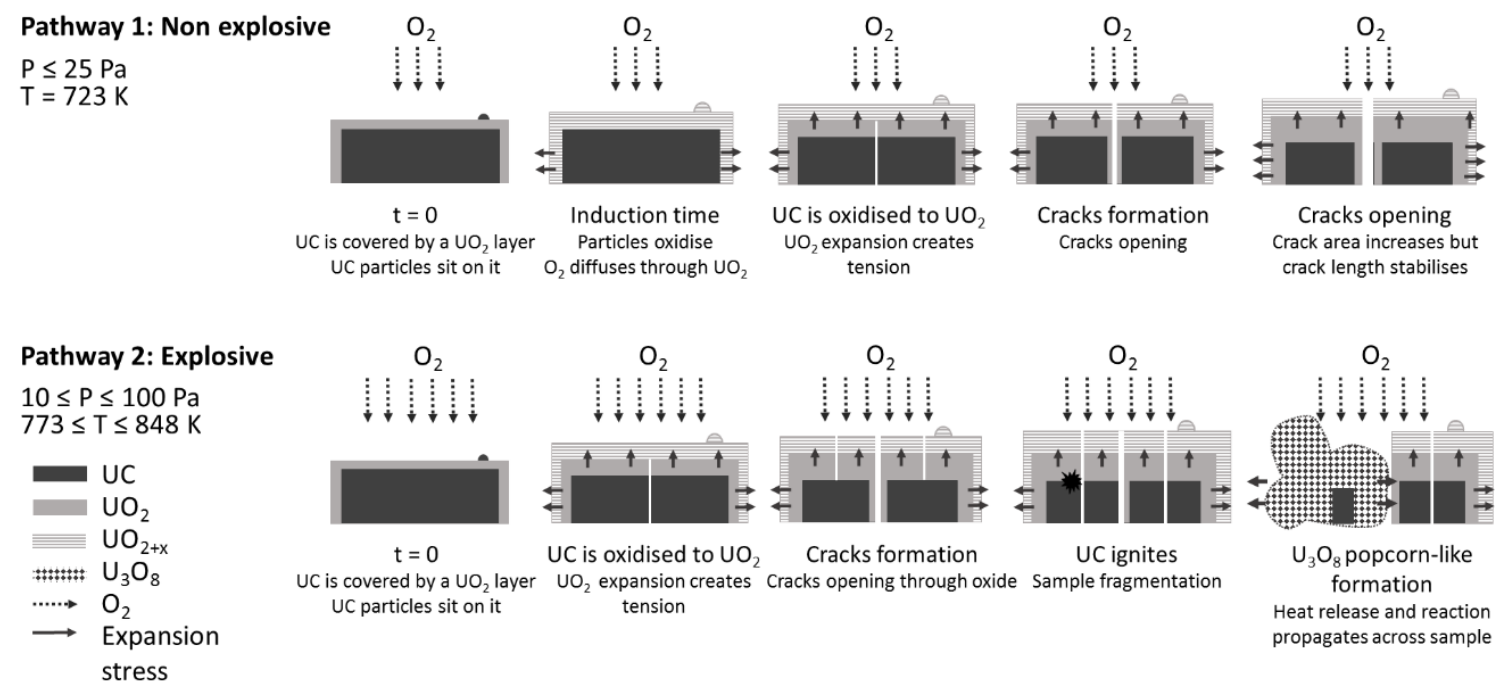

Figure 9. Proposed mechanism of oxidation of UC sintered fragments from $723-848 \mathrm{~K}$ in an oxygen atmosphere of $10-100 \mathrm{~Pa} \mathrm{O}_{2}$.

- Pathway 1. T = 723 K, P $\leq 25 \mathrm{~Pa}$ : non explosive

(i) Induction time: UC small particles (approximately $3 \mu \mathrm{m}$ wide) on the surface oxidise while sample area remains (presumably) stable as cracks are not formed. During this period oxygen can be agglomerated in the oxide layer.

(ii) Sample starts to expand: oxygen passes through the protective oxide layer and comes into contact with core UC. This process is described by both Equations 1 and 2, the formation of $\mathrm{UO}_{2}$ creates stresses on the surface as this transformation implies a volume increase of $34 \%$ (see Table 3) which provokes sample expansion and crack formation. Crack propagation and sample area expansion first exponentially increase, with a time constant $t_{1}$ $\geq 740 \pm 49$ seconds, and then drop off to low rates following a logarithmic trend.

(iii) At the end of the experiment crack length stabilises: no new cracks form. Oxygen keeps penetrating through the cracks but reactive surface area does not increase.

- Pathway 2. $\mathrm{T}=723 \mathrm{~K}$ and $\mathrm{P}=50 \mathrm{~Pa}, 773 \leq \mathrm{T} \leq 848 \mathrm{~K}$ and $10 \leq \mathrm{P} \leq 100 \mathrm{~Pa}$ : explosive

(i) Induction time is not experimentally observed as oxidation occurs rapidly. UC soon oxidises into $\mathrm{UO}_{2}$ (Equations 1 and 2), this transformation is accompanied by a $34 \%$ volume increase. Sample area, crack area and crack length follow an exponential growth law (Equation 5). The time constant for the sample area expansion is $\leq 470 \pm 14$ seconds describing a high rate of oxidation. 
(ii) Crack length increase is accompanied by a sharp increase of reactive surface area as cracks join in a network. Fragmentation of the sample follows as oxidation proceeds on all the surfaces exposed to the oxygen atmosphere

(iii) Oxygen comes into contact with the fragmented UC core and ignition occurs, this acts as initiation point of the SHS reaction which is visible in Figure 6. The reaction propagates through the sample within a few seconds and the new sample surface gets a popcorn-like morphology. The oxidation products for the sample oxidised at $723 \mathrm{~K}$ are a mixture of $\mathrm{U}_{3} \mathrm{O}_{8}$ and $\mathrm{U}_{3} \mathrm{O}_{7}$.

The main phenomena which are involved in UC oxidation are: ignition of UC, presence of carbon which oxidises into $\mathrm{CO}_{2}$, volumetric expansion between $\mathrm{UC}$ to $\mathrm{UO}_{2}$ and from $\mathrm{UO}_{2}$ to $\mathrm{U}_{3} \mathrm{O}_{8}$ and crack propagation. These phenomena are individually discussed below.

\section{- Ignition of UC}

Usually SHS is used to fabricate carbides, nitrides and also complex oxides by reacting a higher oxide of one metal with a lower oxide of usually another metal. The characteristics of this process are: the adiabatic temperature for combustion is below the melting points of the reactants, the gas phase products is very small and the combustion wave which is self-sustained propagates with a velocity that ranges from $0.1-4.5 \mathrm{~cm} / \mathrm{s}^{40,43}$. The difference between the combustion speed found in this study, approximately $150-500 \pm 50 \mu \mathrm{m} / \mathrm{s}$, with the ones previously reported by Shuck et al. ${ }^{43}$ and Munir et al. ${ }^{40}$ from 0.1 to $4.5 \mathrm{~cm} / \mathrm{s}$ is related to the fact that SHS reactions reported in literature consider as initial material a fine powder, while in this case the runaway reaction initiates on a sintered sample when the reactive surface area reaches a critical point. Particle size of the powder was found to have a great influence on propagation wave velocity, for example by increasing the particle size from 0.05 to $3 \mathrm{~mm}$ Munir et al. observed a velocity drop from $4.5 \mathrm{~cm} / \mathrm{s}$ to $0.7 \mathrm{~cm} / \mathrm{s}$ in a mixture of titanium and carbon ${ }^{40}$. A SHS reaction is associated with a combustion process after local initiation which can be induced using different methods such as placing a coil wire ${ }^{44}$, by laser radiation or by spark ignition ${ }^{45}$. Here the spark initiation is provided by ignition of UC. As can be seen in Table 1 the proposed ignition reaction of UC directly to $\mathrm{U}_{3} \mathrm{O}_{8}{ }^{2}$ (Equation 4) releases the highest amount of heat in comparison with all the other reactions present in the system. At this stage heat release is confined within the fragmented UC core, the nearby UC fragments are therefore heated and consequently self-ignite propagating the reaction through the entire sample.

A correlation between the time needed for ignition to occur and oxygen partial pressure shown in Figure $7 \mathrm{~b}$ is in agreement with a numerical prediction performed by Hughes et al. ${ }^{46}$ for a different system that considers competing exothermic and endothermic chemical reactions in parallel with water evaporation ${ }^{46}$. Their numerical prediction was performed by considering the simplest model where mass transport phenomena such as diffusion and advection are neglected as all gaseous and liquid phases are considered evenly distributed.

\section{- Presence of $\mathbf{C}$ as UC or free $\mathbf{C}$}

It has been reported here that the occurrence of an explosive-like reaction is dependent on oxygen partial pressure (see Figure $7 \mathrm{~b}$ ). The presence of both $\mathrm{U}_{3} \mathrm{O}_{7}$ and $\mathrm{U}_{3} \mathrm{O}_{8}$ in the oxide at the end of the experiment, and the fact that Equation 3 is said to happen after carbon transforms into $\mathrm{CO}$ and/or $\mathrm{CO}_{2}{ }^{28}$ suggests 
that gases are released during sample explosive expansion. However, a direct correlation between the $\mathrm{CO}_{2}$ release and sample explosion cannot be drawn as it was not possible here to monitor the gas evolution.

\section{- Volumetric transformation between $\mathrm{UC}$ and $\mathrm{UO}_{2}$ and $\mathrm{U}_{3} \mathrm{O}_{8}$}

The main explanation associated with the characteristic popcorn like morphology of $\mathrm{U}_{3} \mathrm{O}_{8}$ is usually attributed to the $36 \%$ increase in volume (see Table 3) during conversion from $\mathrm{UO}_{2}{ }^{17}$. This is related to the fact that most of the work on uranium oxidation is based on $\mathrm{UO}_{2}{ }^{22,47,48}$. It is well reported that cracks form in $\mathrm{UO}_{2}$ single crystals when they oxidise to $\mathrm{U}_{3} \mathrm{O}_{7}{ }^{16,49}$ and formation of $\mathrm{U}_{3} \mathrm{O}_{7}$ is an intermediate step that usually occurs when $\mathrm{UO}_{2}$ oxidises to $\mathrm{U}_{3} \mathrm{O}_{8}{ }^{50}$. In the case of $\mathrm{UC}$ oxidation, shown in our study, additional transformations occur. $\mathrm{UC}$ is first oxidised to $\mathrm{UO}_{2}$, then hyperstoichiometric $\mathrm{UO}_{2}$ is converted into $\mathrm{U}_{3} \mathrm{O}_{7}$, possibly to $\mathrm{U}_{4} \mathrm{O}_{9}$ and then to $\mathrm{U}_{3} \mathrm{O}_{8}$ with the release of $\mathrm{CO}_{2}$ gas due to carbon oxidation. In previous in situ $\mathrm{UO}_{2}$ oxidation experiments the popcorn morphology of $\mathrm{U}_{3} \mathrm{O}_{8}$ was associated with crack formation, according to Quémard et al. ${ }^{16}$. In their study the oxidised and popcornlike $\mathrm{U}_{3} \mathrm{O}_{8}$ sample had a similar outline to the initial $\mathrm{UO}_{2}$ sample. In our experiments instead the sample's outline is completely altered by the explosive phenomenon indicating that the popcorn-like transformation is due to ignition of UC.

Table 3. Space groups, specific volumes, densities, lattice parameters and volume changes associated with transformation between uranium monocarbide and uranium oxides ${ }^{39}$

\begin{tabular}{|c|c|c|c|c|c|c|c|c|}
\hline $\begin{array}{l}\text { Uranium } \\
\text { compound }\end{array}$ & $\begin{array}{l}\text { Space } \\
\text { Group }\end{array}$ & $\begin{array}{c}\text { Cell } \\
\text { Volume } \\
\left(\mathbf{n m}^{\mathbf{3}}\right) \\
\end{array}$ & $\begin{array}{c}\mathrm{Z} \\
\text { number }\end{array}$ & $\begin{array}{l}\text { Density } \\
\left(\mathrm{g} / \mathrm{cm}^{3}\right)\end{array}$ & $\begin{array}{c}\text { Lattice } \\
\text { Paramet } \\
\text { er }(\AA)\end{array}$ & $\begin{array}{c}\text { Angle } \\
\left(^{\circ}\right)\end{array}$ & $\begin{array}{c}\text { Transformati } \\
\text { on }\end{array}$ & $\begin{array}{c}\text { Volume } \\
\text { change } \\
(\%) \\
\end{array}$ \\
\hline $\begin{array}{c}\text { UC } \\
\text { Cubic }\end{array}$ & Fm-3m & 0.122 & 4 & 13.61 & 4.96 & 90 & & \\
\hline $\begin{array}{c}\mathbf{U O}_{2} \\
\text { Cubic }\end{array}$ & Fm-3m & 0.163 & 4 & 10.98 & 5.467 & 90 & $\mathrm{UC} \rightarrow \mathrm{UO}_{2}$ & +34 \\
\hline $\begin{array}{c}\alpha-\mathrm{U}_{3} \mathrm{O}_{8} \\
\text { orthorhombic }\end{array}$ & $\mathrm{C} 2 \mathrm{~mm}$ & 0.333 & 6 & 8.39 & $\begin{array}{c}a=6.71 \\
b=11.96 \\
c=4.14\end{array}$ & $\begin{array}{l}90 \\
90 \\
90\end{array}$ & $\mathrm{UO}_{2} \rightarrow \mathrm{U}_{3} \mathrm{O}_{8}$ & +36 \\
\hline
\end{tabular}

The $\mathrm{U}_{3} \mathrm{O}_{8}$ phase formed after popcorn-like transformation is a textured phase, as reported in Figure $7 \mathrm{~b}$, as only some directions are seen in the SAD. The planes seen are the (001), (130) and (002). The fact that the points related to the (001) are rather intense can be explained with the epitaxial theory of Allen et al. ${ }^{51,52,53}$ and confirmed by Taylor et al. ${ }^{17}$ : the oxidation occurring with a rapid rate in the $\mathrm{UO}_{2}$ [111] direction causes the formation of $\mathrm{U}_{3} \mathrm{O}_{8}$ in the [001] direction due to the epitaxial relation that exists between these crystallographic directions ${ }^{17}$. However, in polycrystalline samples the lattice expansion is not readily accommodated as the $\mathrm{UO}_{2}$ parallel to the (111) plane cannot easily expand orthogonally to the surface ${ }^{17}$. This will create a build-up of stress in the oxide structure followed by an increase in crack formation which provokes a drastic modification in the original shape of the sample.

\section{CONCLUSIONS}


The morphological changes during transition from $\mathrm{UC}$ to $\mathrm{U}_{3} \mathrm{O}_{8}$ have been investigated for the first time during UC oxidation at $723-848 \mathrm{~K}$ from $10-100 \mathrm{~Pa} \mathrm{O}_{2}$. Sample area expansion and crack propagation were monitored thanks to the use of an in situ technique: HT-ESEM. This is, to the best of our knowledge, the first time that an oxidation mechanism has been described by measuring the sample morphological changes in situ: surface expansion, crack propagation and crack length. Our method expands on the results found by Quémard et al. ${ }^{16}$ on in situ oxidation of $\mathrm{UO}_{2}$. In their study the sigmoid shape of the weight gain curve describing oxidation of $\mathrm{UO}_{2}$ has been related to the macro cracking process starting when a $\mathrm{UO}_{2+\mathrm{x}}$ layer is formed on the surface.

In this work, we have shown that the transformation from $\mathrm{UO}_{2+\mathrm{x}}$ to $\mathrm{U}_{3} \mathrm{O}_{8}$ occurred after an explosive reaction which propagated as a SHS reaction throughout the sample. This was triggered by UC ignition which occurred at $723 \mathrm{~K}$ in a $50 \mathrm{~Pa} \mathrm{O}_{2}$ atmosphere and for all samples exposed to higher temperatures, from $773 \mathrm{~K}$ to $848 \mathrm{~K}$ in an oxygen atmosphere of $10-100 \mathrm{~Pa} \mathrm{O}_{2}$. UC ignition initiated after a drastic exponential growth of the sample area and crack propagation. The morphology of the oxide before and after this transformation showed that the oxide layers previously arranged in a compact structure were disrupted. Samples that did not oxidise via an explosive pathway showed $\mathrm{UO}_{2}$ as a main oxide product, in this case, sample expansion followed an exponential increase followed by a decrease in rate which fits well to a logarithmic law. At this stage cracks are no longer forming. A proposed model for UC oxidation is shown in Figure 9. Pathway 1 shows the non explosive oxidation occurring when UC oxidises to $\mathrm{UO}_{2}$ while pathway 2 describes the explosive mechanism involved when UC ignition triggers the oxidation from $\mathrm{UO}_{2}$ to $\mathrm{U}_{3} \mathrm{O}_{8}$. The explosive pathway is characterised by fragmentation of the sample due to the high oxidation rate accompanied by an exponential increase of crack propagation and crack length which increased the sample reactive surface area. A criterion for pathway 1 or 2 to occur was found to be related with the time constant, $\mathrm{t}_{1}$. Samples that did undergo explosive reaction had a $t_{1} \leq 470 \pm 14$ seconds while samples that followed pathway 1 are characterised by a $t_{1} \geq 740 \pm 49$ seconds.

\section{ACKNOWLEDGMENTS}

The authors are grateful to the EPSRC DISTINCTIVE (Decommissioning, Immobilisation and Storage soluTIons for NuClear wasTe InVEntories) Consortium for their financial support of this project (EPSRC Industrial Case Award EP/M507428/1 Grant and the DISTINCTIVE EP/ L014041/1 Grant). We also thank Dr Mahmoud Ardakani for help with HRTEM analysis at Imperial College, Dr Stéphanie Szenknect for sample preparation and Joseph Lautru for help with the SEM at ICSM.

1. IAEA - International Atomic Energy Agency. Thermophysical Properties of Materials for Nuclear Engineering: A tutorial and Collection of data. (IAEA-THPH, 2008).

2. Dell, M. \& Wheeler, V. J. The ignition of uranium mononitride and uranium monocarbide in oxygen. J. Nucl. Mater. 21, 328-336 (1966).

3. Berthinier, C., Coullomb, S., Rado, C., Blanquet, E., Boichot, R. \& Chatillon, C. Experimental study of uranium carbide pyrophoricity. Powder Technol. 208, 312-317 (2011).

4. Peakall, K. A. \& Antill, J. E. Oxidation of uranium monocarbide. J. Less-Common Met. 4, 426-435 (1962).

5. Naito, K., Kamegashira, N., Kondo, T. \& Takeda, S. Isothermal oxidation of uranium 
monocarbide powder under controlled oxygen partial pressures. J. Nucl. Sci. Technol. 13, 260267 (1976).

6. Matzke, H. Effect of humidity on the surface oxidation of UC single crystals at room temperature. J. Appl. Phys. 40, 3819-3824 (1969).

7. Tets, A. Van. Reaction of uranium monocarbide powder in oxidizing atmospheres. Thermochim. Acta 6, 195-203 (1973).

8. Matcheret, G. L'oxydation des carbures d'uranium par des reactifs gazeux. Commissariat à l'Energie Atomique Report, BIB-183 (1970).

9. Ohmichi, T. \& Honda, T. The oxidation of UC and UN powder in air. J. Nucl. Sci. Technol. 5, 600-602 (1968).

10. Coppersthwaite, D. P. Options for the recovery of surplus uranium carbide fuel. Technical Report RAT 3432, Issue 01. (BNFL Commercial, 2002).

11. Mukerjee, S. K., Rao, G. A. R., Dehadraya, J. V., Vaidya, V. N., Venugopal, V. \& Sood, D. D. The oxidation of uranium monocarbide microspheres. J. Nucl. Mater. 210, 97-106 (1994).

12. Mazaudier, F., Tamani, C., Galerie, a. \& Marc, Y. On the oxidation of (U,Pu)C fuel: Experimental and kinetic aspects, practical issues. J. Nucl. Mater. 406, 277-284 (2010).

13. Shepherd, J. S., Fairweather, M., Hanson, B. C. \& Heggs, P. J. Mathematical model of the oxidation of a uranium carbide fuel pellet including an adherent product layer. Appl. Math. Model. 45, 784-801 (2017).

14. Matzke, H. Science of Advanced LMFBR Fuels : Solid State Physics, Chemistry, and Technology of Carbides, Nitrides, and Carbonitrides of Uranium and Plutonium. (North Holland, 1986).

15. Le Guyadec, F., Rado, C., Joffre, S., Coullomb, S., Chatillon, C. \& Blanquet, E. Thermodynamic and experimental study of UC powders ignition. J. Nucl. Mater. 393, $333-$ 342 (2009).

16. Quémard, L., Desgranges, L., Bouineau, V., Pijolat, M., Baldinozzi, G., Millot, N., Nièpce, J. C. \& Poulesquen, A. On the origin of the sigmoid shape in the $\mathrm{UO}_{2}$ oxidation weight gain curves. J. Eur. Ceram. Soc. 29, 2791-2798 (2009).

17. McEachern, R. J. \& Taylor, P. A review of the oxidation of uranium dioxide at temperatures below $400^{\circ}$ C. J. Nucl. Mater. 254, 87-121 (1998).

18. Walker, D. E. Y. The oxidation of uranium dioxides. J. Appl. Chem. 15, 128-135 (1965).

19. McEachern, R. J., Choi, J. W., Kolár, M., Long, W., Taylor, P. \& Wood, D. D. Determination of the activation energy for the formation of $\mathrm{U}_{3} \mathrm{O}_{8}$ on $\mathrm{UO}_{2}$. J. Nucl. Mater. 249, 58-69 (1997).

20. Garrido, F., Ibberson, R. M., Nowicki, L. \& Willis, B. T. M. Cuboctahedral oxygen clusters in $\mathrm{U}_{3} \mathrm{O}_{7}$. J. Nucl. Mater. 322, 87-89 (2003).

21. Rousseau, G., Desgranges, L., Charlot, F., Millot, N., Nièpce, J. C., Pijolat, M., Valdivieso, F., Baldinozzi, G. \& Bérar, J. F. A detailed study of $\mathrm{UO}_{2}$ to $\mathrm{U}_{3} \mathrm{O}_{8}$ oxidation phases and the associated rate-limiting steps. J. Nucl. Mater. 355, 10-20 (2006).

22. Hoekstra, H. R., Santoro, A. \& Siegel, S. The low temperature oxidation of $\mathrm{UO}_{2}$ and $\mathrm{U}_{4} \mathrm{O}_{9} . J$. Inorg. Nucl. Chem. 18, 166-178 (1961).

23. Gasparrini, C., Podor, R., Horlait, D., Chater, R. \& Lee, W. E. Zirconium carbide oxidation: maltese cross formation and interface characterization. Oxid. Met. 1-8 (2016).

doi:10.1007/s11085-016-9672-6 
24. Sciti, D., Silvestroni, L., Guicciardi, S., Fabbriche, D. D. \& Bellosi, A. Processing, mechanical properties and oxidation behavior of $\mathrm{TaC}$ and $\mathrm{HfC}$ composites containing $15 \mathrm{vol} \% \mathrm{TaSi}_{2}$ or $\mathrm{MoSi}_{2}$. J. Mater. Res. 24, 2056-2065 (2009).

25. Silvestroni, L. \& Sciti, D. Sintering behavior, microstructure, and mechanical properties: A comparison among pressureless sintered ultra-refractory carbides. Adv. Mater. Sci. Eng. 2010, $1-11(2010)$.

26. Menzies, I. A. \& Strafford, N. The oxidation of uranium-based ceramics. The behaviour of UC and $\mathrm{UO}_{2}$ contaminated with carbon containing phases. J. Nucl. Mater. 21, 287-301 (1967).

27. Besson, J. \& Moureau, C. La réaction de l'oxygène sur le monocarbure d'uranium massif. Compt. Rend. Acad. Sci. Paris 258, 4079-4082 (1964).

28. Iyer, V. S., Mukerjee, S. K., Kamat, R. V, Pillai, K. T., Kumar, N., Vaidya, V. N. \& Sood, D. D. Oxidation behavior of carbide fuels. Nucl. Technol. 91, 388-393 (1990).

29. Scott, C. D. Analysis of combustion of graphite-uranium fuels in a fixed bed or moving bed. Ind. Eng. Chem. Process Des. Dev. 5, 223-233 (1966).

30. Horlait, D., Claparede, L., Tocino, F., Clavier, N., Ravaux, J., Szenknect, S., Podor, R. \& Dacheux, N. Environmental SEM monitoring of $\mathrm{Ce}_{1-\mathrm{x}} \mathrm{Ln}_{\mathrm{x}} \mathrm{O}_{2-\mathrm{x} / 2}$ mixed-oxide microstructural evolution during dissolution. J. Mater. Chem. A 2, 5193-5203 (2014).

31. Clavier, N., Podor, R., Deliere, L., Ravaux, J. \& Dacheux, N. Combining in situ HT-ESEM observations and dilatometry: An original and fast way to the sintering map of $\mathrm{ThO}_{2}$. Mater. Chem. Phys. 137, 742-749 (2013).

32. Podor, R., Pailhon, D., Ravaux, J. \& Brau, H.-P. Development of an integrated thermocouple for the accurate sample temperature measurement during high temperature environmental scanning electron microscopy (HT-ESEM) experiments. Microsc. Microanal. 21, 307-312 (2015).

33. Schneider, C. A., Rasband, W. S. \& Eliceiri, K. W. NIH Image to ImageJ: 25 years of image analysis. Nat. Methods 9, 671-675 (2012).

34. Homann, H. Implementation of a 3D thinning algorithm. Insight J. July-Decem, 4-7 (2007).

35. Arganda-Carreras, I., Fernández-González, R., Muñoz-Barrutia, A. \& Ortiz-De-Solorzano, C. 3D reconstruction of histological sections: Application to mammary gland tissue. Microsc. Res. Tech. 73, 1019-1029 (2010).

36. Kofstad, P. High Temperature Corrosion. (Elsevier Applied Science, London \& New York, 1988).

37. Yang, J. H., Kang, K. W., Kim, K. S., Rhee, Y. W. \& Song, K. W. Recycling process for sinter-active $\mathrm{U}_{3} \mathrm{O}_{8}$ powders. J. Nucl. Sci. Technol. 47, 538-541 (2010).

38. Higgs, J. D., Thompson, W. T., Lewis, B. J. \& Vogel, S. C. Kinetics of precipitation of $\mathrm{U}_{4} \mathrm{O}_{9}$ from hyperstoichiometric $\mathrm{UO}_{2+x}$. J. Nucl. Mater. 366, 297-305 (2007).

39. Guéneau, C., Chartier, A. \& Van Brutzel, L. Book section 2.02: Thermodynamic and thermophysical properties of the actinide oxides. Comprehensive Nuclear Materials - Volume 2 (2012).

40. Munir, Z. A. \& Anselmi-Tamburini, U. Self-propagating exothermic reactions: The synthesis of high-temperature materials by combustion. Mater. Sci. Reports 3, 279-365 (1989).

41. Konings, R. J. M., Morss, L. R. \& Fuger, J. in The chemistry of the Actinide and Transactinide Elements 2113-2224 (Springer, 2006). 
42. Lefort, P., Desmaison, J. \& Billy, M. Comportement du nitrure de niobium cubique $\delta$ en atmosphere d'oxygene. Mater. Res. Bullettin 14, 479-486 (1979).

43. Shuck, C. E., Manukyan, K. V., Rouvimov, S., Rogachev, A. S. \& Mukasyan, A. S. Solidflame: Experimental validation. Combust. Flame 163, 487-493 (2016).

44. Holt, J. B. \& Munir, Z. A. Combustion synthesis of titanium carbide : theory and experiment. J. Mater. Sci. 21, 251-259 (1986).

45. Barzykin, V. V. Initiation of SHS processes. Pure Appl. Chem. 64, 909-918 (1992).

46. Hughes, K. J., Brindley, J. \& McIntosh, A. C. Initiation and propagation of combustion waves with competitive reactions and water evaporation. Proc. R. Soc. A Math. Phys. Eng. Sci. 469, 20130506-20130506 (2013).

47. Hoekstra, H. R., Siegel, S., Fuchs, L. H. \& Katz, J. J. The uranium-oxygen system: $\mathrm{UO}_{2.5}$ to $\mathrm{U}_{3} \mathrm{O}_{8}$. J. Phys. Chem. 59, 136-138 (1955).

48. Blackburn, P. E., Weissbart, J. \& Gulbransen, E. A. Oxidation of uranium dioxide. J. Phys. Chem. 62, 902-908 (1958).

49. Desgranges, L., Palancher, H., Gamaléri, M., Micha, J. S., Optasanu, V., Raceanu, L., Montesin, T. \& Creton, N. Influence of the $\mathrm{U}_{3} \mathrm{O}_{7}$ domain structure on cracking during the oxidation of $\mathrm{UO}_{2}$. J. Nucl. Mater. 402, 167-172 (2010).

50. Poulesquen, A., Desgranges, L. \& Ferry, C. An improved model to evaluate the oxidation kinetics of uranium dioxide during dry storage. J. Nucl. Mater. 362, 402-410 (2007).

51. Allen, G. C., Tempest, P. A. \& Tyler, J. W. Characterisation of crystalline $\mathrm{UO}_{2}$ oxidised in 1 Torr of oxygen at 25,225 and $300^{\circ}$ C. Part 1. X-ray photoelectron spectroscopy. J. Chem. Soc. Faraday Trans. 1 Phys. Chem. Condens. Phases 84, 4049-4059 (1988).

52. Allen, G. C., Tempest, P. A. \& Tyler, J. W. The formation of U3O8 on crystalline UO2. Philos. Mag. Part B 54, L67-L71 (1986).

53. Allen, G. C., Tempest, P. A. \& Tyler, J. W. Characterisation of crystalline $\mathrm{UO}_{2}$ oxidised in 1 Torr of oxygen at 25,225 and $300{ }^{\circ} \mathrm{C}$. Part 2. X-ray diffraction and scanning electron microscopy. J. Chem. Soc. Faraday Trans. 1 Phys. Chem. Condens. Phases 84, 4061-4072 (1988). 